\title{
Genetic Analysis on the Role of Integrin during Axon Guidance in Drosophila
}

\author{
Bao Hoang and Akira Chiba \\ Department of Cell and Structural Biology, University of Illinois, Urbana, Illinois 61801
}

\begin{abstract}
Heterodimeric cell surface receptor integrin is widely expressed in the nervous system, but its specific role during axon development has not been directly tested in vivo. We show that the Drosophila nervous system expresses low levels of positronspecific (PS) integrin subunits $\alpha \mathrm{PS} 1, \alpha \mathrm{PS} 2$, and $\beta \mathrm{PS}$ during embryonic axogenesis. Furthermore, certain subsets of neurons express higher levels of integrin mRNAs than do the rest. Null mutations in either the $\alpha \mathrm{PS} 1$ or $\alpha \mathrm{PS} 2$ subunit gene cause widespread axon pathfinding errors that can be rescued by supplying the wild-type integrin subunit to the mutant nervous
\end{abstract}

system. In contrast, misexpressing either the $\alpha \mathrm{PS} 1$ or $\alpha \mathrm{PS} 2$ integrin subunit in all neurons leads to no obvious axon pathfinding errors. We propose that integrin does not itself serve as either a "clutch" constituting molecule or a specific growth cone "receptor," as proposed previously, but rather as part of a molecular network that cooperatively guarantees accurate axon guidance.

Key words: $\alpha P S 1 ; \alpha P S 2$; axon guidance; $\beta P S$; Drosophila; growth cone; inflated; integrin; multiple edematous wings; myospheroid; neuromuscular; pathfinding
Axon guidance relies on the activation of cell surface receptors that translate extrinsic cues into directed cytoskeletal rearrangement within a growth cone (Chiba and Keshishian, 1996; Goodman, 1996; Jay, 1996). Recent studies establish that many members of integrin, a cell adhesion/signaling molecule, are widely distributed in developing nervous systems (Schmidt et al., 1995; Varnum-Finney et al., 1995; Jones, 1996; Lallier et al., 1996; Martin et al., 1996; Shaw et al., 1996; Wu et al., 1996; Grotewiel et al., 1998). In vitro studies show that integrin is enriched at the tip of a growing axon, suggesting a role in axon guidance (Wu et al., 1996; Grabham and Goldberg, 1997; Takagi et al., 1998). One model proposes that integrin is an important component of the "clutch," a molecular complex that is responsible for growth cone advancement by anchoring cytoplasmic actin filaments to the extracellular substrate (C. H. Lin et al., 1994; Schmidt et al., 1995). Another model predicts that integrin serves as a cellspecific recognition "receptor" that biases growth cone movement toward the ligand source (Kuhn et al., 1995, 1998). These ideas have not been tested in vivo.

We chose Drosophila as a model system for studying integrins because its nervous system consists of well-defined axon pathways (Chiba, 1998) and because it has a small set of integrin subunits similar in structure and function to those in vertebrates (MacKrell et al., 1988; Leptin et al., 1989; Wilcox, 1990; Brown, 1993, 1994; Yee and Hynes, 1993; Gotwals et al., 1994a,b; Brower et al., 1995; Bunch et al., 1998). A positron-specific (PS) $\alpha$ PS1 subunit

\footnotetext{
Received April 21, 1998; revised July 13, 1998; accepted July 17, 1998.

This work was supported by National Institutes of Health Grant NS35049, National Science Foundation Grant IBN-95-14531, and the Lucille P. Markey Charitable Trust (A.C.). We thank Dan Brower and Mike Graner (University of Arizona), Karen Stark (Massachusetts Institute of Technology), Corey Goodman (University of California at Berkeley), and Emiko Suzuki (University of Tokyo) for generous gifts of reagents. We also thank Hiroyuki Kose (National Institute of Genetics, Japan) and Yasumitsu Takagi (Tsukuba Research Consortium, Japan) for discussion and Anna Huttenlocher, Steven Kaufman, Xiaomao Zhu, and the current members of the Chiba Lab (University of Illinois) for comments on this manuscript.

Correspondence should be addressed to Dr. Akira Chiba, B605 Chemical and Life Science Laboratory, 601 South Goodwin Avenue, Urbana, IL 61801.

Copyright (C) 1998 Society for Neuroscience $0270-6474 / 98 / 187847-09 \$ 05.00 / 0$
}

(structurally similar to vertebrate laminin-responsive $\alpha 3, \alpha 6$, and $\alpha 7$ subunits) dimerizes with an $\beta$ PS subunit (similar to the vertebrate $\beta 1$ subunit) to form the laminin-binding PS1 integrin. An $\alpha \mathrm{PS} 2$ subunit (similar to vertebrate RGD-dependent $\alpha 5, \alpha 8, \alpha \mathrm{v}$, and $\alpha \mathrm{IIb}$ subunits) also dimerizes with the $\beta \mathrm{PS}$ subunit to form PS2 integrin that binds to molecules with the amino acid triplet RGD (e.g., tiggrin). These PS integrins serve as major cell adhesion molecules during embryogenesis, with PS1 integrin concentrated in ectodermal and endodermal tissues and PS2 integrin being most abundant in mesodermal tissues (Zusman et al., 1990; Bunch et al., 1992; Roote and Zusman, 1996). A role for PS integrins in embryonic neuronal differentiation has been speculated because $\beta$ PS loss-of-function mutants fail to condense the CNS normally during early larvagenesis and primary neuronal culture from these mutants fail to develop normally on a laminin substrate (Donady and Seecof, 1972; Brown, 1994). The $\alpha$ PS3 subunit, a new member of the PS integrin family that dimerizes with a $\beta$ PS subunit, has also been detected in the embryonic nervous system (Stark et al., 1997). Both laminin and tiggrin, known ligands for PS1 and PS2 integrins, respectively, are present along the embryonic axon pathways (Montell and Goodman, 1989; Fogerty et al., 1994). Despite all circumstantial evidence that they may be involved in neural development, expression patterns of PS integrins as well as their specific role during neuronal development have not yet been examined.

In this study, we show that PS integrins ( $\alpha$ PS1, $\alpha$ PS2, and $\beta$ PS subunits) are expressed in the embryonic nervous system, starting during the period of axogenesis, and we provide genetic evidence that neuronally expressed integrins are directly involved in axon development.

\section{MATERIALS AND METHODS}

Fly stocks. Null alleles for the $\alpha \mathrm{PS} 1$ integrin subunit gene multiple edematous wings are $y^{1}$ mew $^{\mathrm{M} 6} f^{36 \mathrm{a}} p\left[r y^{+\mathrm{t} 7.2}:\right.$ :newFRT ${ }^{18 \mathrm{~A}} / F M 7 c_{\mathrm{ftz}}$-lacz $(\mathrm{a}$ null allele) and $y^{1}$ mew $^{498} p\left[r y^{+17.2}: \text { newFRT }\right]^{18 \mathrm{~A}} / F M 7 c$ (a protein null allele); loss-of-function alleles for the $\alpha \mathrm{PS} 2$ integrin subunit gene inflated are $g^{2}$ if ${ }^{\mathrm{K} 27 \mathrm{E}} f^{36 \mathrm{a}} / F M 7 c_{\mathrm{ftz}}$-lacz (a null allele) and $g^{2}$ if $\mathrm{f}^{\mathrm{B} 2} f^{36 \mathrm{a}} / F M 7 c$ (a hypomorphic allele with an $\sim 10 \%$ protein expression level) (Brabant and Brower, 1993; Brower et al., 1995) (source, K. Stark, Massachusetts 

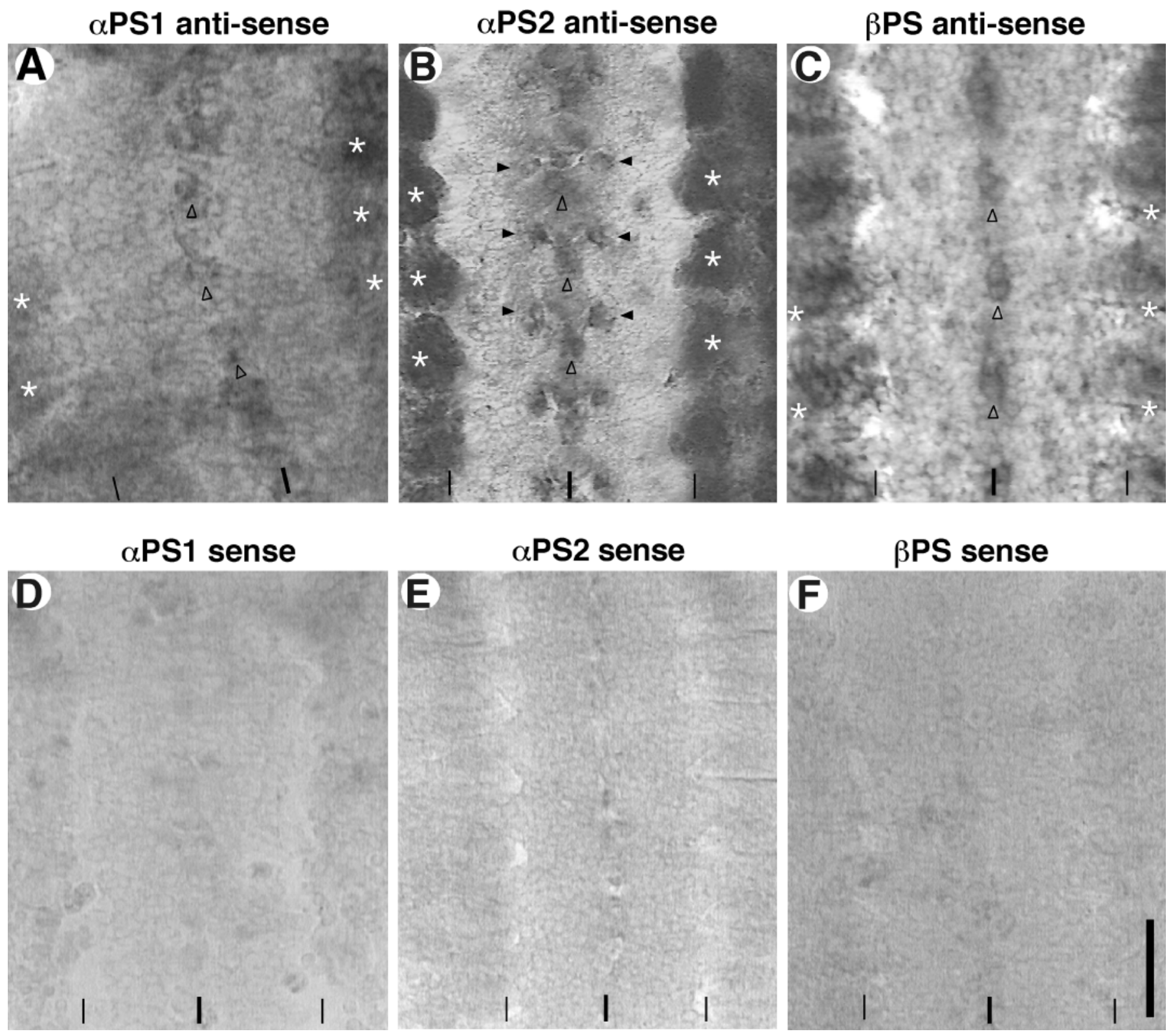

Figure 1. PS integrin mRNA in the wild-type Drosophila embryonic CNS at hour 15. Embryos were probed with either antisense or sense (control) mRNA for the PS integrin subunits (see Materials and Methods). Panels show five abdominal segments of the CNS and surrounding mesoderm and/or ectodermal tissues in fillet-dissected preparations. All photos were taken at the focal planes slightly above the ventral surface of the CNS, except for $(B)$ and $(E)$ that are focused $\sim 10 \mu \mathrm{m}$ below the dorsal surface of the CNS. The ventral midline and the lateral edges of the CNS are indicated by thick and thin vertical lines, respectively, at the bottom of each panel. Anterior is to the top of each panel. $A, \alpha \mathrm{PS} 1 \mathrm{mRNA}$ is expressed widely within the CNS, with slightly higher expression in a cluster of cells at the ventral midline (open arrowheads). Expression in the peripheral tissues (asterisks) is higher than that in the CNS. $B, \alpha \mathrm{PS} 2 \mathrm{mRNA}$ is also widely expressed in the CNS. A midline cluster (open arrowheads) and bilaterally paired mediolateral clusters (closed arrowheads) of unidentified cells have noticeably high levels of expression. Muscles express $\alpha \mathrm{PS} 2$ at very high levels (asterisks). $C, \beta \mathrm{PS}$ mRNA expression is also widespread. Relatively high levels of expression are seen in the CNS cells near the ventral midline (open arrowheads). Outside the CNS, both apodemes and muscles show high expression levels (asterisks). $D-F$, Sense mRNA for each of the three PS subunits served as negative controls for the in situ hybridization procedures. Scale bar: vertical line in $F, 20 \mu \mathrm{m}$.

Institute of Technology, and Bloomington Fly Stock Center, Bloomington, IN). All of these mutations reach lethality by early larval stages. The genotypes of individual embryos examined were confirmed immunologically using the appropriate PS subunit antibodies, which reveal the presence or absence of particular PS subunits, and/or $\beta$-galactosidase antibodies, which detect the $F M 7 c$ balancer chromosome that carries the marker transgene $f t z$ '-lacZ (see Immunocytochemistry). For "neuron" rescue experiments, wild-type $\alpha \mathrm{PS} 2$ gene was supplied to the nervous system in $\alpha \mathrm{PS} 2$ null mutants (if ${ }^{\mathrm{K} 27 \mathrm{E}}$ ) by the use of the GAL4 misexpression system (Brand et al., 1994) that combines a genomic neurotopic enhancer "elav'-GAL4 "III" (Sone et al., 1997) (source, E. Suzuki, Univer- sity of Tokyo) to the GAL4-responsive transgene "UAS- $\alpha P S 2^{\mathrm{wt}}$ " (Roote and Zusman, 1996) (source, D. Brower, University of Arizona): if ${ }^{\mathrm{K} 27 \mathrm{E}} / Y$; $U A S-\alpha P S 2^{\mathrm{wt}} / e l a v '-G A L 4^{\mathrm{III}}$. Misexpression of $\alpha \mathrm{PS} 1$ and $\alpha \mathrm{PS} 2$ was achieved by, respectively, $G A L 4^{\mathrm{C} 155} /+$ (or $Y$ ); UAS- $\alpha P S 1^{\mathrm{wt}} /+$ and $G A L 4^{\mathrm{C} 155} /+($ or $Y) ; U A S$ - $\alpha P S 2^{\mathrm{wt}} /+$, in which $G A L 4^{\mathrm{C} 155}$, a GAL4 "enhancer trap" line (D. M. Lin et al., 1994) (source, C. Goodman, University of California at Berkeley), targets misexpression to all neurons similar to the "elav'-GAL4 ${ }^{\mathrm{III}}$ " line. Canton $S$ strain was used as a wild-type control. In addition, the $\beta$ PS null mutant line $\left(m y s^{\mathrm{xb} 87} / Y\right)$ (Leptin et al., 1989) (source, K. Stark) was examined as a negative control for the immunocytochemistry data. 


\section{wild type}

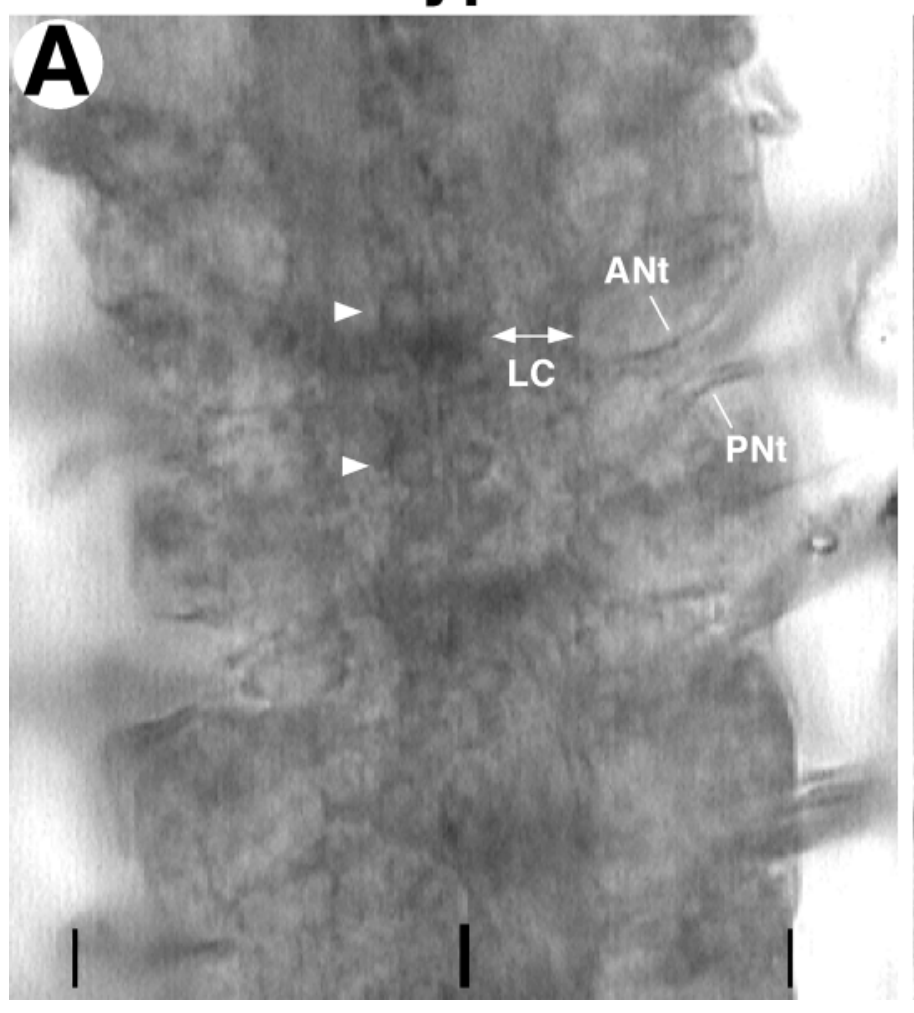

$\beta P S$ null mutant

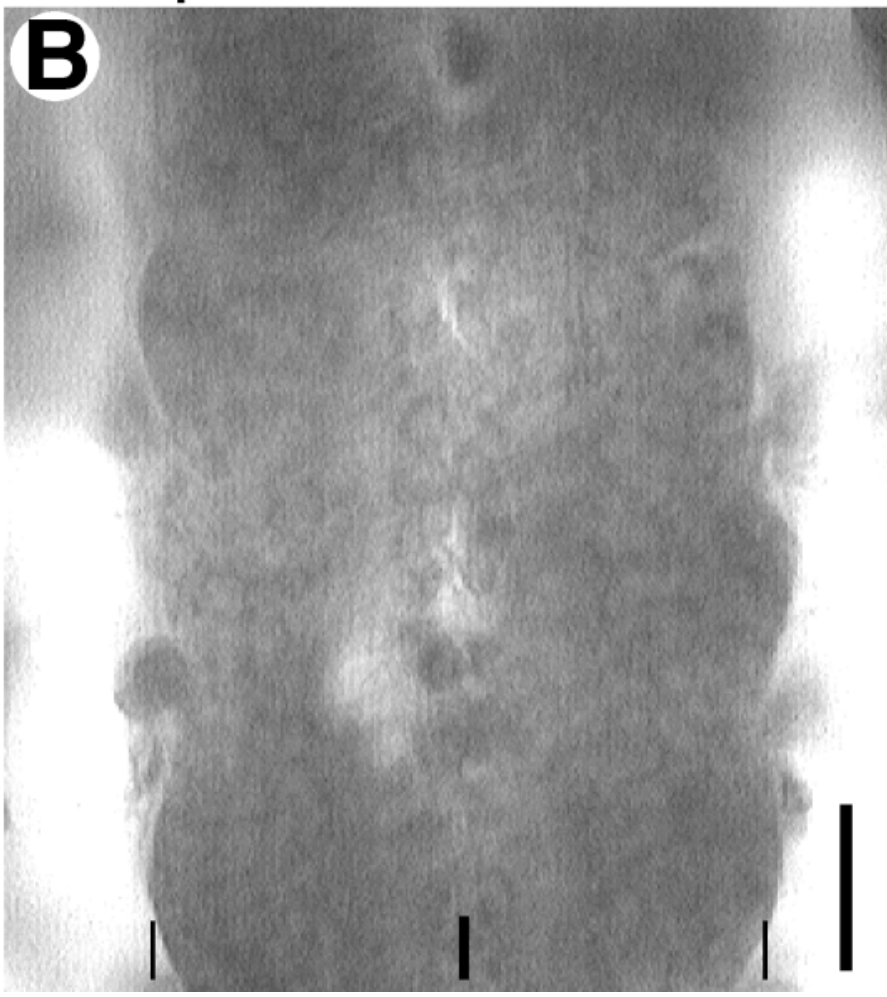

Figure 2. $\quad \beta$ PS integrin protein subunit in the embryonic CNS at hour 18. Fillet-dissected embryos were processed for $\beta$ PS immunocytochemistry (see Materials and Methods). Panels show four abdominal CNS segments. $A$, In a wild-type embryo $(F M 7 c / Y)$, the $\beta$ PS protein subunit is detected in the major axon tracts that include the pair of longitudinal connectives $(L C)$ as well as the anterior nerve tract $(A N t)$ and the posterior nerve tract $(P N t)$. The latter two axon tracts contain motoneuron axons. In addition, surfaces of many neuronal cell bodies, including those of the pair of RP3 motoneurons at this focus (arrowheads), accumulate low levels of the $\beta$ PS protein subunit. $B, \beta$ PS null embryo $\left(m y s^{x b 87} / Y\right)$, which has been dissected and immunoprocessed in the same minipool as the wild-type control, shows only the nonspecific background staining and serves as a negative control. Scale bar, $20 \mu \mathrm{m}$.

In situ hybridization. cDNAs for $\alpha \mathrm{PS} 1$ (multiple edematous wings gene), $\alpha \mathrm{PS} 2$ (inflated gene), and $\beta \mathrm{PS}$ (myospheroid gene) were subcloned into pBluescript to prepare digoxygenin-labeled antisense and sense (negative control) RNA probes (Bogaert et al., 1987; MacKrell et al., 1988; Wehrli et al., 1993) (source, D. Brower). Wild-type 9-18 hr whole embryos were processed for in situ hybridization and probed with RNA at concentrations of $\sim 1 \mathrm{ng} / \mathrm{ml}$ ( $\beta \mathrm{PS}$ and $\alpha \mathrm{PS} 1$ ) and $\sim 5 \mathrm{ng} / \mathrm{ml}(\alpha \mathrm{PS} 2)$ for $2-3 \mathrm{hr}$ (Broadus and Doe, 1995). The entire set of in situ hybridization experiments was repeated independently three times to confirm reproducibility of the staining patterns.

Immunocytochemistry. Primary antibodies were as follows: $\mathrm{mAb}$ CF.6G11 ( $\beta$ PS subunit; 1:1000 dilution), mAb DK.1A4 ( $\alpha$ PS1 subunit; 1:500 dilution), mAb CF.2C7 ( $\alpha$ PS2 subunit; 1:500 dilution) (Wilcox et al., 1981; Brower et al., 1984) (source, D. Brower), mAb 1D4 (1:4 dilution) (Grenningloh et al., 1991) (source, C. Goodman), and anti- $\beta$ galactosidase (1:5000 dilution) (source, Promega, Madison, WI). Embryos were immunoprocessed as whole embryos or after fillet dissection on glass slides with "minipools" (Chiba et al., 1993). The mutant embryos were analyzed by double-immunolabeling with mAb 1D4 that stains CNS axon fascicles and motoneuron axons and an antibody against the respective integrin subunit and/or $\beta$-galactosidase (see Fly stocks). To preserve antigenicities for the PS subunits, we incubated the embryos with the primary antibodies before fixation. Analysis was based on abdominal A2-A7 segments of fillet-dissected preparations.

\section{RESULTS}

\section{Embryonic neurons express PS integrins during axogenesis}

We examined the expression pattern of $\alpha$ PS1, $\alpha$ PS2, and $\beta$ PS subunits using in situ hybridization and immunocytochemistry in the embryonic nervous system (see Materials and Methods). All three PS subunit mRNAs are expressed widely in the nervous system (Fig. 1). Their expression levels during hours 9-18 of embryogenesis are notably low compared with that in the other tissues that have been studied previously, such as muscles and apodemes (Fig. $1 A-C$, asterisks). $\alpha$ PS1 mRNA is detected widely in the CNS at a steady level during hours 13-18 (Fig. $1 A$ ). During this period, axogenesis occurs within the CNS as well as in the periphery. At the ventral midline, cells appear to accumulate slightly higher levels of $\alpha \mathrm{PS} 1$ compared with most other cells in the CNS (Fig. $1 A$, open arrowheads). The $\alpha \mathrm{PS} 2$ mRNA expression pattern differs somewhat from that of $\alpha$ PS1. Specific clusters of cells, one near the midline and a bilateral pair at mediolateral sites, express at relatively high levels of $\alpha \mathrm{PS} 2$ in each segment of the CNS (Fig. $1 B$, arrowheads). The $\alpha \mathrm{PS} 2$ expression in the CNS peaks during hours $9-15$ of embryogenesis. The $\beta$ PS mRNA expression pattern partially overlaps with those of $\alpha \mathrm{PS} 1$ and $\alpha \mathrm{PS} 2$ mRNA in the CNS, with one prominent cluster of cells expressing relatively high levels at the ventral midline (Fig. 1C, open arrowheads). $\beta$ PS mRNA expression in the CNS persists through hours $9-18$. These in situ hybridization data suggest that the embryonic CNS expresses both PS1 ( $\alpha$ PS1/ $\beta$ PS heterodimer) and PS2 ( $\alpha$ PS $2 / \beta$ PS heterodimer) integrins during the period of axogenesis.

Consistent with the mRNA data, immunocytochemistry shows 
wildtype

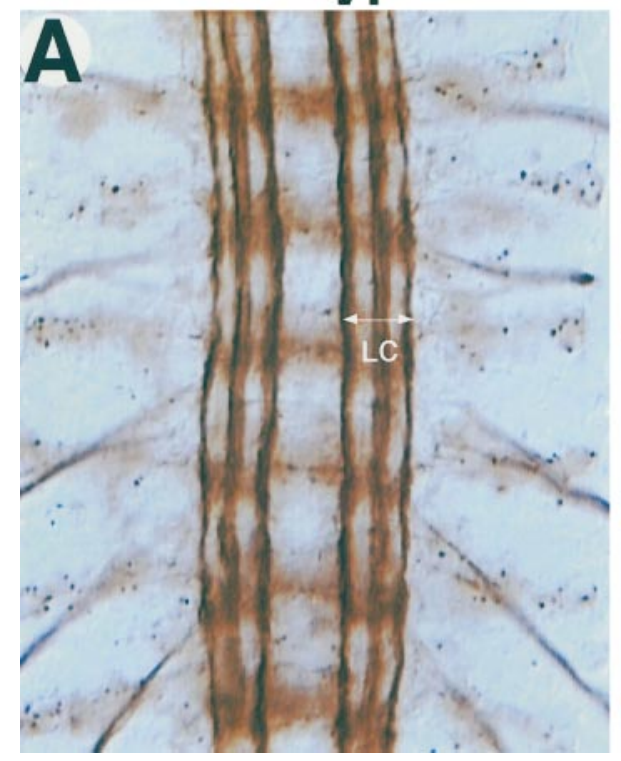

null mutant

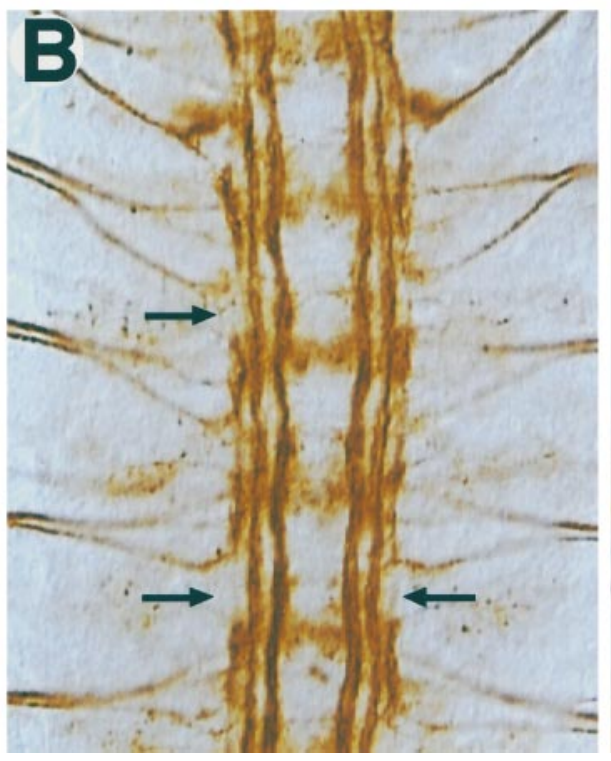

null mutant

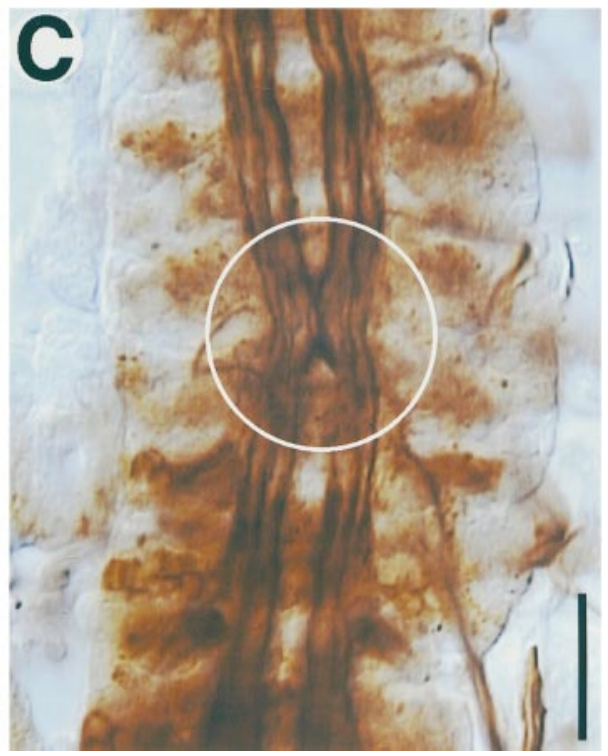

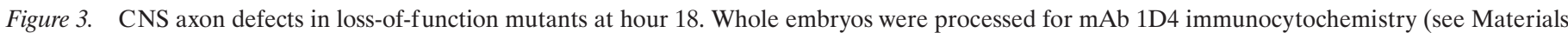

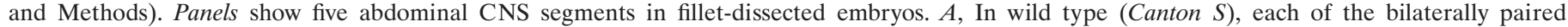

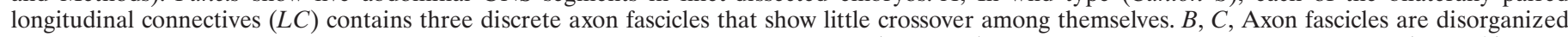

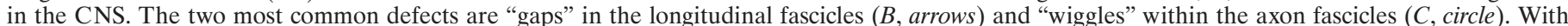

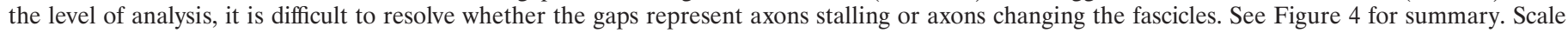
bar, $20 \mu \mathrm{m}$.

that the $\beta$ PS protein subunit is unambiguously revealed on neuronal cell surfaces during hours $16-18$ (Fig. $2 A$ ). The major axon fascicles within the CNS, including the longitudinal connectives and the anterior and posterior nerve tracts (Fig. $2 A$ ), as well as the cell surfaces of at least some identified neurons, are labeled with the $\beta$ PS antibodies (Fig. $2 A$, arrowheads). Unfortunately, both $\alpha$ PS1 and $\alpha$ PS2 subunits are below the threshold of detection with available antibodies. However, the detection of the $\beta$ PS protein subunit on the neuronal cell surfaces suggests that the $\alpha$ PS subunits are likely forming functional heterodimers with the $\beta$ PS subunit in those cells. These observations with in situ hybridization and immunocytochemistry have led us to conclude that, similar to vertebrate neurons, many Drosophila neurons express relatively low levels of integrin on the neuronal surface during axogenesis.

\section{Loss of integrin disrupts axon guidance}

To analyze the role of the PS integrins in developing axons, we examined mutant embryos lacking the functional gene for either the $\alpha \mathrm{PS} 1$ or $\alpha \mathrm{PS} 2$ subunit. In these mutants, unlike in the $\beta \mathrm{PS}$ null mutants that exhibit grossly abnormal muscle development (Leptin et al., 1989), muscles develop apparently normally up to hour 18 through the major period of embryonic axogenesis. There is little sign that neuronal cell bodies have migrated to incorrect positions, in addition to the fact that the entire nervous system develops relatively normally. On closer examinations, however, both $\alpha$ PS1 and $\alpha$ PS2 loss-of-function mutant alleles exhibit similarly widespread and variable axon guidance defects (Fig. 3B,C). In the CNS, the longitudinal connective normally contains three prominent axon fascicles that are easily visualized by mAb 1D4 (Fig. $3 A$ ). Axons in the mutants appear somewhat wiggly (Fig. $3 C$, circle) or partially disconnected (Fig. $3 B$, arrows). The results are summarized in Figure 4.

In the PNS, one can visualize specific groups of motoneuron axons with higher cellular resolution than is possible in the CNS. Null mutations in $\alpha \mathrm{PS} 1$ and $\alpha \mathrm{PS} 2$ subunit genes both result in similarly widespread axon pathfinding defects for all five known motoneuron groups, despite apparently normal muscle development (Fig. $5 G-L$ ). The axon defects observed can be interpreted as a consequence of failing to turn at choice points and/or invading into neighboring muscle fields (Fig. 5, arrows, circles). These defects are most frequently detected in the $\mathrm{SNb}$ group (Fig. $4 D, F)$. It is important to note that the axons in these loss-of-function mutants can extend as far as in wild type and sometimes up to $30 \mu \mathrm{m}$ beyond their normal stopping points (Fig. $5 J$, circle). This suggests that integrin is unlikely to serve simply as a clutch-constituting molecule, on which growth cones depend for the adequate traction needed to extend forward. Another point is that each axon group selects a range of alternative pathways without obvious preferences. It is therefore likely that the loss of integrin leads to losses in the responsiveness of an axon to a large array, rather than a small specific set, of guidance cues. Finally, in general, loss of PS2 integrin ( $\alpha$ PS2 null mutation) leads to higher axon guidance errors than does loss of PS1 integrin ( $\alpha$ PS1 null mutation). Future analysis is needed to determine specific contributions of these two forms of integrin. On the basis of the current data, we suggest that both the laminin-binding PS1 and RGD-dependent PS2 integrins are necessary for accurate axon guidance.

\section{Axon guidance defects are rescued by supplying the wild-type integrin}

To test the direct role of integrin in axon development further, we attempted to rescue the axon defects by using a genomic neurotopic enhancer to drive expression of wild-type integrin gene in the nervous system of the null mutant (see Materials and Methods). We chose to focus on the $\alpha$ PS2 null mutants because they showed more severe PNS defects than did the $\alpha$ PS1 null 

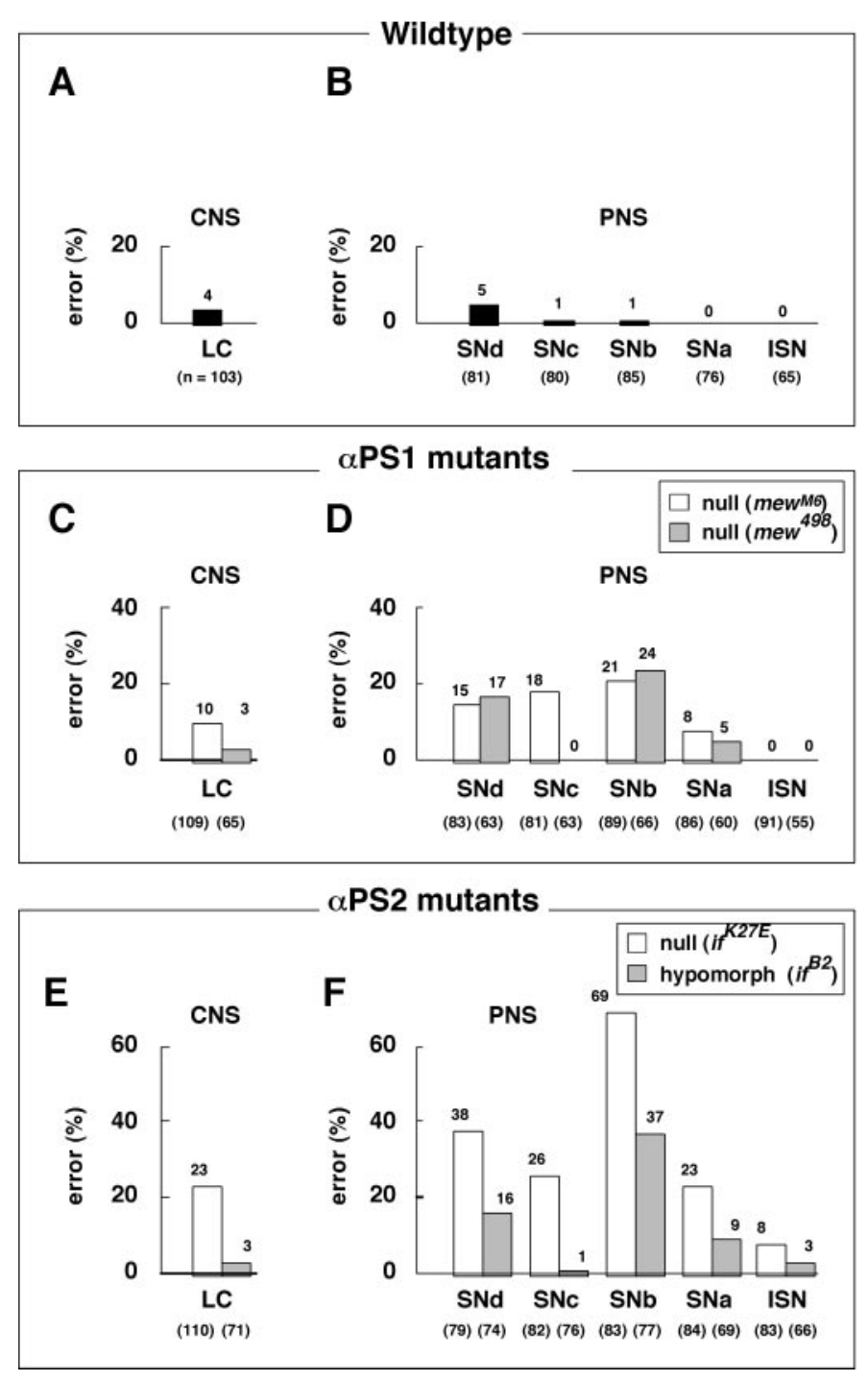

Figure 4. Summary of axon defects in loss-of-function mutants. Data are based on the hour 18 embryos after immunoprocessing with mAb 1D4 and fillet dissection. CNS axon fascicles were analyzed only in the longitudinal connectives $(L C)$. Various classes of defects, such as the gaps and wiggles shown in Figure 3, $B$ and $C$, are included as axon "errors." In the periphery, all five groups of motoneuron axons ( $I S N, S N a, S N b, S N c$, and $S N d$ ) were examined. In each group, axon defects are collectively summarized as errors. Examples of various peripheral nervous system (PNS) axon defects are shown below (see Fig. 5G-L). Both the error rates and sample sizes (the numbers of abdominal hemisegments scored; numbers in parentheses below each bar) are indicated in the charts. The data for the $\alpha \mathrm{PS} 1$ mutants are based on $10 \mathrm{mew}^{\mathrm{M} 8}$ and eight mew $^{498}$ embryos, and the penetrance of the axon errors either in the CNS or PNS in each allele is $\sim 90 \%$. Similarly, the data for the $\alpha \mathrm{PS} 2$ mutants are based on nine $m e w^{\mathrm{M} 8}$ and eight $m e w^{498}$ embryos, and the penetrance of the axon errors either in the CNS or PNS ranges between 78 and 100\%. There is no obvious correlation between the CNS and PNS segments in which axon defects occur. Taken together, these observations support the idea that the loss of integrin leads to widespread and stochastic axon guidance errors throughout the nervous system. $A, B$, Wild type (Canton $S$ ) shows very low axon error rates $(0-5 \%)$ in the CNS $(A)$ as well as in the periphery (PNS) $(B)$. The data are based on eight embryos. $C, D, \alpha \mathrm{PS} 1$ null mutants $\left(\right.$ mew $^{\mathrm{M} 6} / Y$ and $\left.m e w^{498} / Y\right)$ both show low-to-medium rates $(0-24 \%)$ of axon errors in the CNS $(C)$ and PNS $(D) . E, F$, The $\alpha$ PS2 null mutant allele $\left(i f^{\mathrm{K} 27 \mathrm{E}} / Y\right)$ exhibits medium-to-high rates $(8-69 \%)$ of axon errors in the CNS $(E)$ and PNS $(F)$. The hypomorphic allele $\left(i f^{\mathrm{B} 2} / Y\right)$ shows similar defects at slightly reduced rates $(1-37 \%)$. mutants (Fig. 6). The overall expression levels of the $\alpha \mathrm{PS} 2$ protein subunit in this neuron rescue experiment were low and hardly detectable via immunocytochemistry, approximately mimicking endogenous expression in the CNS (data not shown). Consistent with a direct role for integrin, guidance defects are primarily rescued in both the CNS longitudinal connectives and the peripheral motor pathways (Figs. 6, 7). This result suggests that axons rely on their own integrin while responding accurately to local guidance cues.

\section{Integrin misexpression results in little growth cone guidance errors}

How does neuronal integrin facilitate accurate axon guidance? A simple model is that integrin itself serves as a receptor for specific guidance cues, in much the same way as do a number of cell surface receptors (see Discussion). To test this idea, we expressed integrin ubiquitously in the wild-type CNS so that it would be present in neurons that normally express little or no integrin. We predicted that, if integrin serves as a receptor for specific growth cone guidance cues, many neurons with normally low or no integrin expression would alter their axon pathways. Contrary to our prediction, we found that axons exhibit little pathfinding error in either the CNS or periphery when either the $\alpha \mathrm{PS} 1$ or $\alpha \mathrm{PS} 2$ gene is misexpressed ubiquitously in the nervous system (Fig. 8). These results, as well as the results from the loss-of-function analysis described above, suggest that integrin is not likely to serve as a specific guidance receptor in vivo.

\section{DISCUSSION}

In this study, we have shown that integrin ( $\alpha \mathrm{PS} 1, \alpha \mathrm{PS} 2$, and $\beta \mathrm{PS}$ subunits) is present in the developing Drosophila nervous system and have provided evidence that neuronal integrin is required for accurate axon guidance in vivo.

\section{Neuronal integrin guides axons}

Integrin, one of the best-studied classes of cell adhesion/signaling molecules in animals, has been shown to link intercellular signaling systems to a number of intracellular signaling pathways (Parsons, 1996; Schlaepfer and Hunter, 1998). It is expressed dynamically in a variety of cells during development wherein extensive intercellular communication is required. Evidence of potential roles of integrin during axon development is available from in vitro experiments (Schmidt et al., 1995; Varnum-Finney et al., 1995; Felsenfeld et al., 1996; Shaw et al., 1996; Wu et al., 1996; Grabham and Goldberg, 1997). However, recent mouse knockout experiments fail to demonstrate the specific in vivo role of integrin during axon development, primarily because of the large number of integrin isoforms and their widespread expression patterns (Hynes, 1996). Therefore, to date, an in vivo demonstration of the roles of integrin in axon guidance has not been available.

Our genetic analysis on the Drosophila embryonic nervous system provides two lines of evidence that neuronal integrin is essential for accurate axon guidance. First, in the loss-of-f unction mutants for the $\alpha$ PS1 or $\alpha$ PS2 subunit gene, axons in the CNS and the periphery both exhibit widespread guidance errors (see Fig. 4 for summary). In the PNS, with its relatively simple cellular landscape, the miswired axons are seen frequently to extend beyond normal target regions (Fig. 5J,L). Therefore, although lack of integrin does not reduce general motility of growth cones, the accuracy of their guidance is diminished. Second, genetic 
A

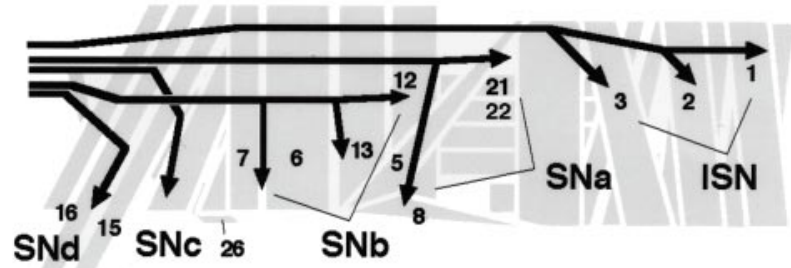

\section{wildtype}
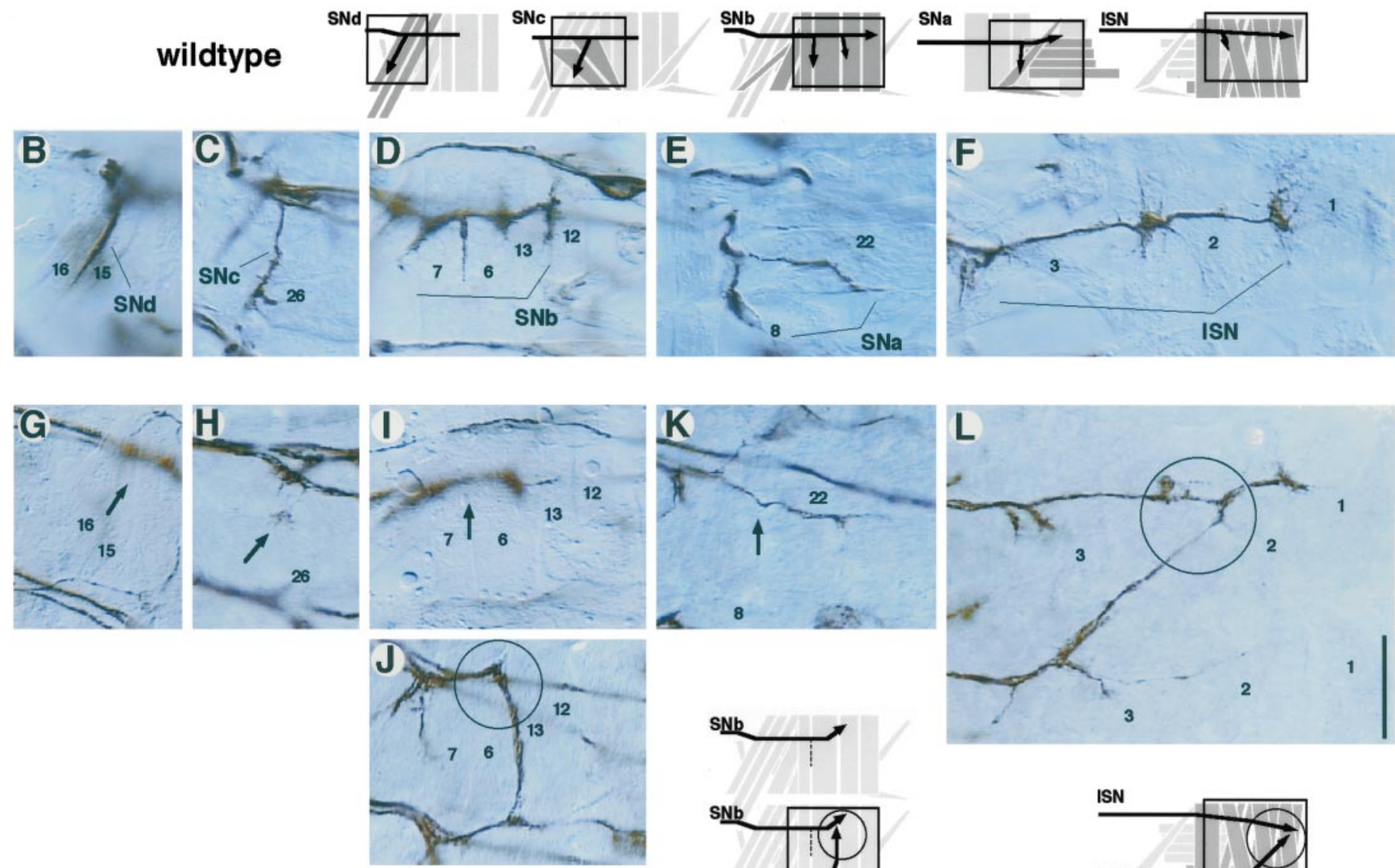

null mutant
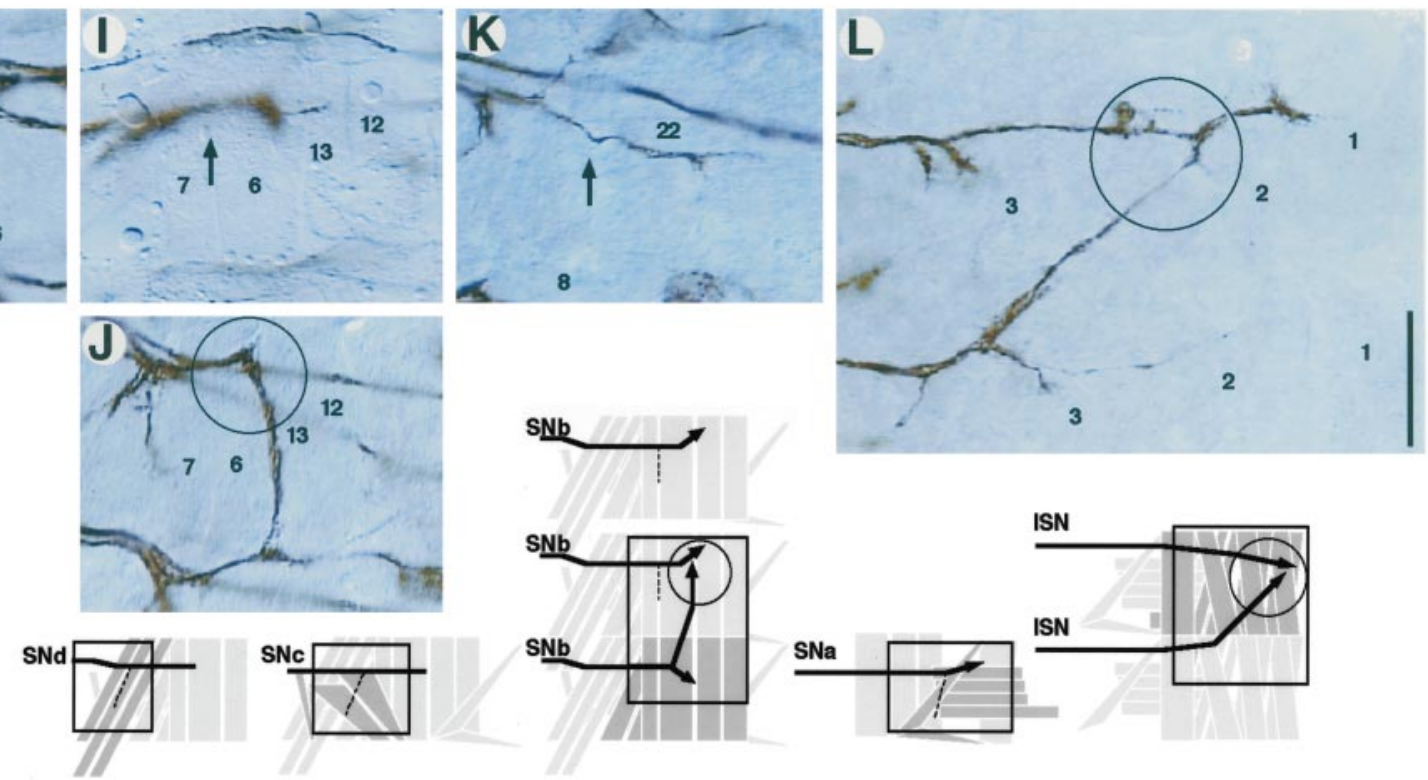

Figure 5. PNS axon defects in loss-of-function mutants at hour 18. Embryos were processed for mAb 1D4 immunocytochemistry and fillet-dissected. $B-L$ show parts of the motoneuron axon pathways in a right PNS hemisegment. Boxes in the schematics above and below B-J approximately correspond to the areas shown in the panels. A, Each hemisegment contains 30 uniquely identified muscles and is innervated by five groups (fascicles) of motoneuron axons: $S N d, S N c, S N b, S N a$, and $I S N$. The muscles that are targeted by each motoneuron group are labeled with identification numbers (13 of 30). B-F, In wild type (Canton $S), S N d$ targets the ventral- (proximal) most muscles including 15 and $16(B)$. SNc targets the next ventral-most muscles including 26 (C). SNb branches into several subfascicles and innervates ventrolateral muscles including 6, 7, 12, and $13(D)$. The $S N a$ motoneuron group extends toward the lateral muscles and bifurcates into two subfascicles; one subfascicle reaches transverse muscles 21 , 22, and others, whereas another turns posteriorly to innervate 5 and $8(E)$. ISN extends farthest and targets the dorsal- (distal) most muscles such as 1,2 , and $3(F)$. $G-L$, In the null mutant embryos, the PNS axon fascicles exhibit various defects. The types of axon pathfinding defects seen for the $\alpha$ PS1 and $\alpha$ PS2 null mutants are very similar. $S N d$ and $S N c$ are sometimes missing $(G, H$,arrows). Axons that would normally reach this muscle region may be either stalling or bypassing. $S N b$ frequently extends beyond the normal stopping point and invades into the neighboring segment $(J$, circle) or fails to form sub-branches at muscles 6 and 7 (I, arrow). SNa occasionally misses its posteriorly directed sub-branch and fails to innervate muscles 5 and 8 (K, arrow). ISN sometimes fails to obey segmental boundaries and merges with the ISN from adjacent segments $(L$, circle). See Figure 4 for data summary. Scale bar, $20 \mu \mathrm{m}$.

rescue reverts the axonal defects toward the wild type (Figs. 6, 7). The fact that this is achieved by resupplying low levels of the wild-type integrin gene specifically to the nervous system of otherwise null mutant embryos strongly suggests that integrin is directly involved in the axon guidance.

\section{Neuronal integrin and its low expression levels}

Previous studies on Drosophila PS integrins have focused mostly on their involvement during the development of non-neuronal tissues, including wing epithelia, muscle attachment sites, dorsal vessels, and gut (Leptin et al., 1989; Wilcox et al., 1989; Wilcox, 


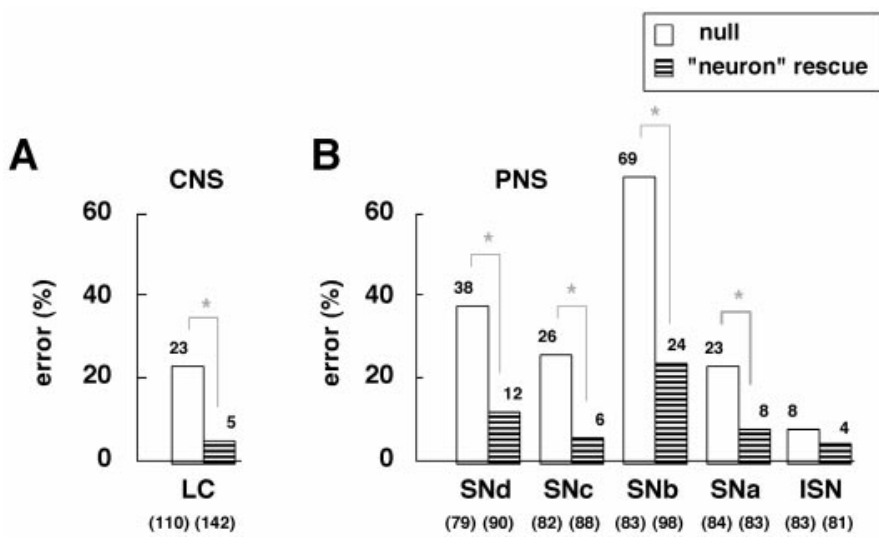

Figure 6. $A, B$, The axon defects in $\alpha \mathrm{PS} 2$ null mutants (if ${ }^{\mathrm{K} 27 \mathrm{E}} / Y$ ) can be partially rescued by supplying wild-type $\alpha \mathrm{PS} 2$ gene to the nervous system in the mutant background (striped bars; if ${ }^{\mathrm{K} 27 \mathrm{E}} / Y$; UAS- $\alpha P S 2^{\mathrm{wt}} /$ elav'- $^{\text {' }}$ GAL4 ${ }^{\text {III }}$; see Materials and Methods). In this neuron rescue experiment, the rates of axon defects in both the CNS $(A)$ and PNS $(B)$ revert toward those of wild type, yielding error rates significantly lower than those in $\alpha \mathrm{PS} 2$ null mutants (asterisks; $p<0.001$ by $\mathrm{Chi}^{2} t$ test). (See Fig. 7 for examples.) The parental lines used for the neuron rescue experiment were either wild-type-like (UAS- $\alpha P S 2^{\text {wt }}$ and elav'-GAL4 $\left.{ }^{\mathrm{III}}\right)$ or indistinguishable from the $\alpha \mathrm{PS} 2$ null mutants $\left(f^{\mathrm{K} 27 \mathrm{E}} / Y ; U A S-\alpha P S 2^{\mathrm{wt}}\right)$ in their axon fascicle organizations.

1990; Zusman et al., 1990; Brown, 1993; Gotwals et al., 1994b; Brower et al., 1995; Fernandes et al., 1996; Stark et al., 1997; Bunch et al., 1998). The primary function of integrin is thought to be that of cell adhesion in these nonmigratory cells. Much less is known about the roles of integrin in the nervous system, where it is expressed at relatively low levels. In vitro work with chick dorsal root ganglion neurons shows that protein kinase
C-dependent cytoplasmic signaling is involved in the behavioral modification of growth cones that occurs after their contacting laminin, the major ligand for integrin (Kuhn et al., 1995). This suggests that in axons, with its relatively low expression levels, integrin may primarily serve as a mediator of cell signaling via its specific association with a variety of cytoplasmic proteins. In vivo analysis on the physiological functions of the cytoplasmic domains of the PS integrin subunits in Drosophila have just begun in a variety of tissues (Martin-Bermudo et al., 1997; Li et al., 1998). It would be interesting to extend such analysis and test the roles of the cytoplasmic domains of integrin in the context of axon guidance.

\section{New models for the role of integrin in axon guidance}

Although our genetic analysis demonstrates that neuronally expressed integrin is essential for accurate axon guidance, the results are inconsistent with some of the previously proposed models concerning the role of integrin in axon development. One model, known as the clutch model, stems from the in vitro observations that, when a growth cone advances, actin filaments inside filopodia are held down to the substrate (Lin and Forscher, 1995). When applied to integrin, this clutch model proposes that integrin, an integral membrane molecule, serves as a mechanical link between specific extracellular substrates and the cytoskeleton and thus provides the traction necessary for growth cone advancement. Support for this "integrin-as-clutch" model comes from an in vitro study in which integrin activation is suggested to lock integrin to actin filaments in filopodia (Felsenfeld et al., 1996). The model predicts that, when integrin is missing, growth cones will lose much of their traction and will reduce their forward motility. However, our in vivo analysis has revealed little reduction in growth cone motility as a result of genetic deletion of the
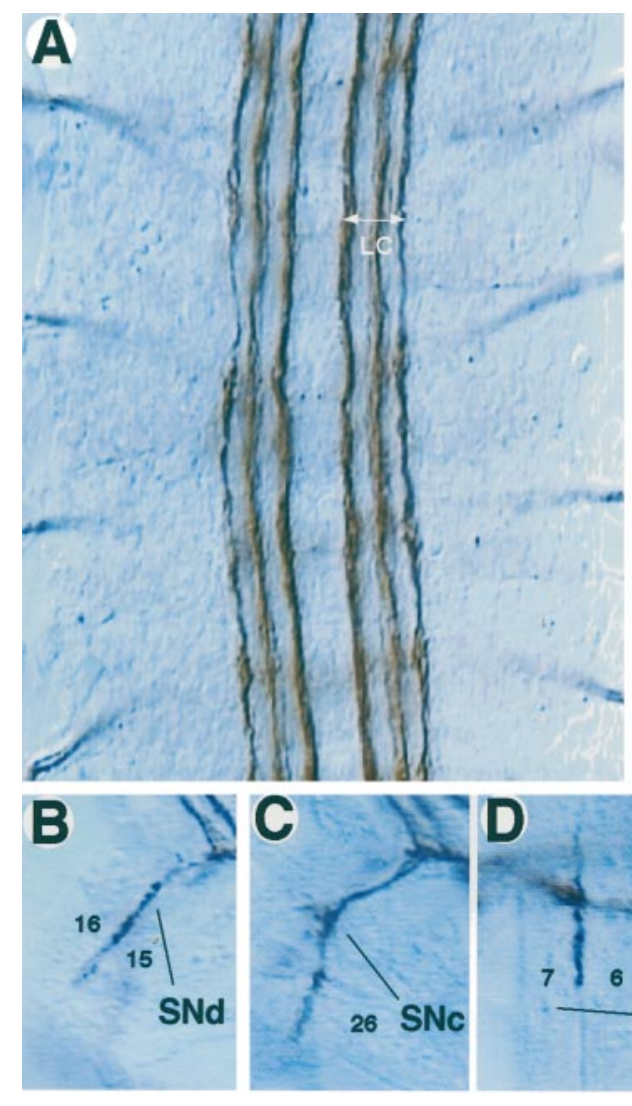

Figure 7. Neuron rescue experiment. Axon fascicle organizations in the $\alpha \mathrm{PS} 2$ null mutant embryos (hour 18) after neuron rescue (see Materials and Methods) were visualized using mAb 1D4. $A$, Four abdominal CNS segments in a fillet-dissected embryo are shown. The longitudinal connectives $(L C)$ revert to virtually wild type and exhibit three discrete fascicles (compare with Fig. $3 A) . B-F$, In the PNS, axon fascicle organizations are very similar to that in wild type (compare with Fig. $5 B-F$ ). Both $S N d(B)$ and $S N c(C)$ innervations are present at high frequencies. $S N b$ axons show much-reduced error rates $(D)$ compared with those in the $\alpha \mathrm{PS} 2$ null mutants (compare with Fig. 5I, J). SNa increases its rate of forming the posteriorly directed sub-branch that reaches muscles 5 and $8(E)$. ISN obeys the segment boundaries and looks very similar to wild type $(F)$. See Figure 6, $A$ and $B$, for data summary. Scale bar, $20 \mu \mathrm{m}$.
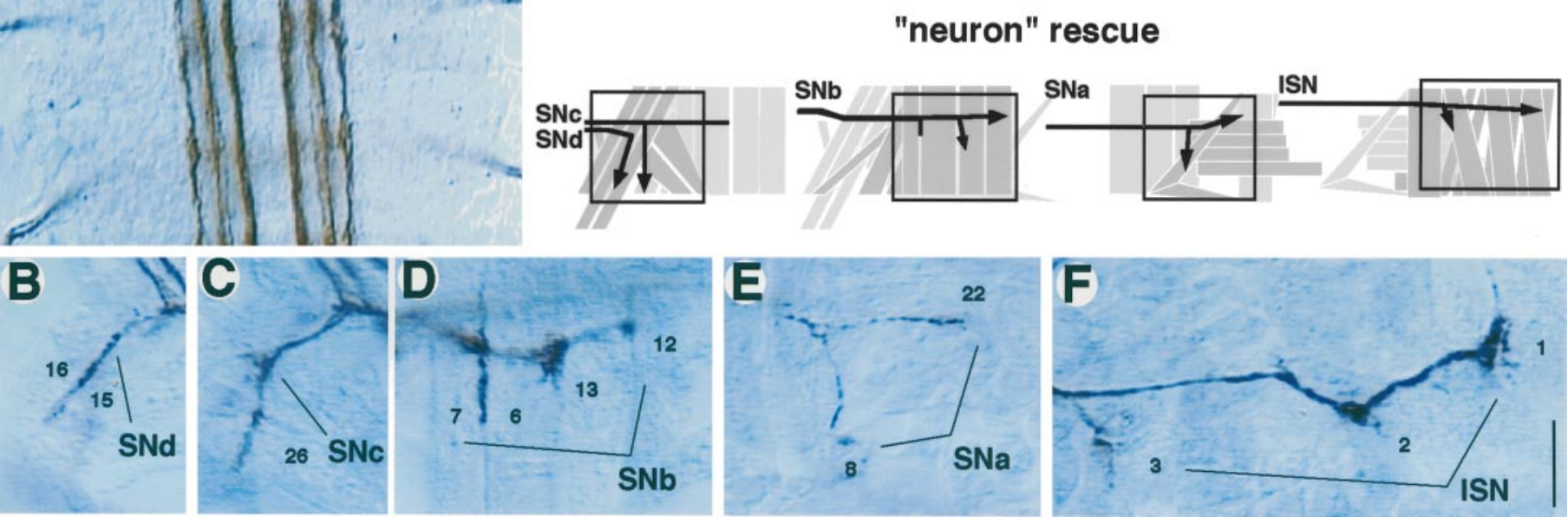

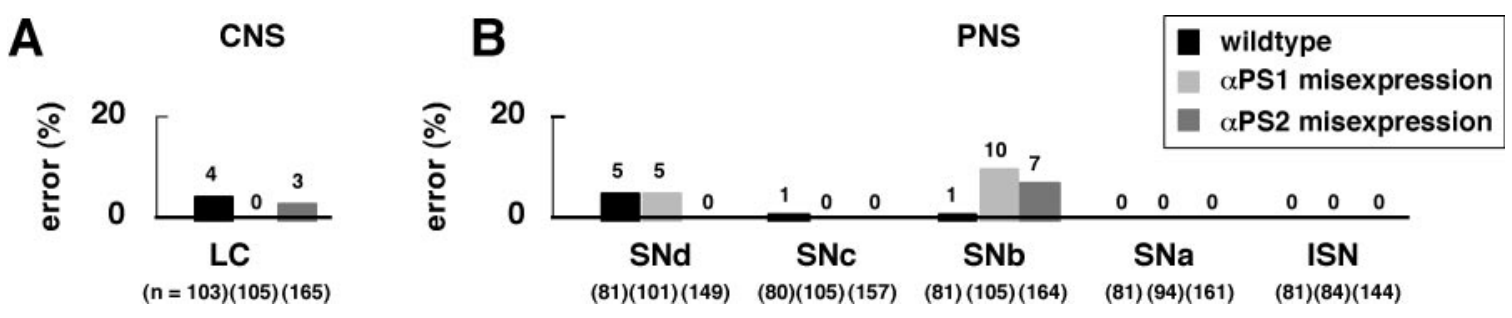

Figure 8. Summary of axon defects in gain-of-function experiments. Data are based on the $18 \mathrm{hr}$ embryos (see Materials and Methods) that were immunoprocessed (mAb 1D4) and fillet-dissected, similar to those in Figures 4 and 6. $A, B$, Low-level neurotopic misexpression of either the $\alpha$ PS1 or $\alpha \mathrm{PS} 2$ gene results in no apparent axon defects in the CNS $(A)$ or PNS $(B)$.

integrin subunits. Instead, there is an increase in growth cone targeting errors. Thus, a simple clutch model does not seem to adequately explain the role of integrin in axon development.

In the alternative receptor model, neuronal integrin itself is proposed to serve a pivotal role in turning a growth cone by reacting to specifically localized extrinsic cues (Kuhn et al., 1995). This model predicts that, when integrin is lacking, growth cones that normally express integrin will select alternative pathways at the choice points where the ligands of integrin are normally present. Along the same line of logic, if integrin is misexpressed in growth cones that normally do not express it, this will alter the pathfinding of these growth cones in specific ways as well. Our observations suggest that this receptor model is not predictive of the role of integrin in axon guidance. It is noteworthy that, in vitro, integrin is clearly capable of exerting enough biases on a growth cone to turn it toward the source of specific ligands such as laminin (Kuhn et al., 1998). However, whether the natural ligands of integrin are distributed in specific patterns in vivo is still not clear. Available evidence hints that laminin and tiggrin, the known ligands for the PS integrins in Drosophila, are both rather ubiquitously expressed along the entire substrate that the majority of neuronal axons grow over (Montell and Goodman, 1989; Fogerty et al., 1994). Therefore, we favor the view that, in vivo, integrin is unlikely to serve as a specific axon guidance receptor.

What then is the role of integrin in the axon guidance, because its absence does lead to widespread loss of guidance accuracy? In one simple model, integrin functions as an adhesion molecule that controls the speed of growth cone advancement. In this "speed control" model, low levels of integrin are necessary to prevent the axons from extending too fast and missing the chance to interact with guidance cues. In a more elaborate model, integrin serves as an interface that links a specific cue recognition at the surface of the growth cone to internal cytoplasmic and cytoskeletal signaling events. In this "interface" model, integrin cooperates with a number of other growth cone receptors, such as EphR family receptor tyrosine kinases, DCC-type netrin receptors, receptor-type phosphotyrosine phosphatases, Fasciclin III, Connectin, and other unknown receptors (Speicher et al., 1998; Treubert and Brummendorf, 1998). Activation of any of these specific growth cone receptors is coupled to integrin-mediated intracellular signaling systems. The model predicts that integrin and associated molecules are rapidly recruited to, and/or activated at, particular filopodia that have contacted a specific target or guidepost cell. It also anticipates that mutations that delete only one of the many different growth cone receptors that are interfaced by integrin do not always produce pronounced axon guidance errors. On the other hand, deleting integrin would cause widespread axon defects, as observed in this study. Integrin, with its extensive opportunity to work with a large array of molecules
(Clark and Brugge, 1995; Schlaepfer and Hunter, 1998), seems to be in an ideal position to signal-amplify a local event of minimal amplitude and to generate a bias large enough to steer a growth cone with accuracy.

\section{REFERENCES}

Bogaert T, Brown N, Wilcox M (1987) The Drosophila PS2 antigen is an invertebrate integrin that, like the fibronectin receptor, becomes localized to muscle attachments. Cell 51:929-940.

Brabant MC, Brower DL (1993) PS2 integrin requirements in Drosophila embryo and wing morphogenesis. Dev Biol 157:49-59.

Brand A, Manoukian AS, Perrimon N (1994) Ectopic expression in Drosophila. In: Methods in cell biology (Goldstein LSB, Fyrberg EA, eds), pp 683-696. San Diego: Academic.

Broadus J, Doe CQ (1995) Evolution of neuroblast identity: seven-up and prospero expression reveal homologous and divergent neuroblast fates in Drosophila and Schistocerca. Development 121:3989-3996.

Brower D, Wilcox M, Piovant M, Smith RJ, Reger LA (1984) Related cell-surface antigens expressed with positional specificity in Drosophila imaginal discs. Proc Natl Acad Sci USA 81:7485-7489.

Brower DL, Bunch TA, Mukai L, Adamson TE, Wehrli M, Lam S, Friedlander E, Roote CE, Zusman S (1995) Nonequivalent requirements for PS1 and PS2 integrin at cell attachments in Drosophila: genetic analysis of the $\alpha$ PS1 integrin subunit. Development 121:1311-1320.

Brown NH (1993) Integrins hold Drosophila together. BioEssays 15:383-390.

Brown NH (1994) Null mutations in the $\alpha$ PS2 and $\beta$ PS integrin genes have distinct phenotypes. Development 120:1221-1231.

Bunch TA, Salatino R, Engelsgjerd MC, Mudai L, West RF, Brower DL (1992) Characterization of mutant alleles of myospheroid, the gene encoding the $\beta$ subunit of the Drosophila PS integrin. Genetics 132:519-528.

Bunch TA, Graner MW, Fessler LI, Fessler JH, Schneider KD, Kerschen A, Choy LP, Burgess BW, Brower DL (1998) The PS2 integrin ligand tiggrin is required for proper muscle function in Drosophila. Development 125:1679-1689.

Chiba A (1998) Early development of Drosophila neuromuscular junction: a model for studying neuronetwork development. In: Neuromuscular junctions in Drosophila (Budnik V, Gramotes S, eds). San Diego: Academic, in press.

Chiba A, Keshishian H (1996) Neuronal pathfinding and recognition: roles of cell adhesion molecules. Dev Biol 180:424-432.

Chiba A, Hing H, Cash S, Keshishian H (1993) Growth cone choices of Drosophila motoneurons in response to muscle fiber mismatch. J Neurosci 13:714-732.

Clark EA, Brugge JS (1995) Integrins and signal transduction pathways: the road taken. Science 268:233-239.

Donady JJ, Seecof RL (1972) Effect of the gene lethal(1) myospheroid on Drosophila embryonic cells in vitro. In Vitro 8:7-12.

Felsenfeld DP, Choquet D, Sheetz M (1996) Ligand binding regulates the directed movement of $\beta 1$ integrins on fibroblasts. Nature 383:438-440.

Fernandes JJ, Celniker SE, Vijay Raghavan K (1996) Development of the indirect flight muscle attachment sites in Drosophila: role of the PS integrins and the stripe gene. Dev Biol 176:166-184.

Fogerty FJ, Fessler LI, Bunch TA, Yaron Y, Parker CG, Nelson RE, Brower DL, Gullberg D, Fessler JH (1994) Tiggrin, a novel Drosophila 
extracellular matrix protein that functions as a ligand for Drosophila $\alpha$ PS2 $\beta$ PS integrins. Development 120:1747-1758.

Goodman CS (1996) Mechanisms and molecules that control growth cone guidance. Annu Rev Neurosci 19:341-377.

Gotwals PJ, Fessler LI, Wehrli M, Hynes RO (1994a) Drosophila PS1 integrin is a laminin receptor and differs in ligand specificity from PS2. Proc Natl Acad Sci USA 91:11447-11451.

Gotwals PJ, Paine-Saunders SE, Stark KA, Hynes RO (1994b) Drosophila integrins and their ligands. Curr Opin Cell Biol 6:734-739.

Grabham PW, Goldberg DJ (1997) Nerve growth factor stimulates the accumulation of $\beta 1$ integrin at the tips of filopodia in the growth cones of sympathetic neurons. J Neurosci 17:5455-5465.

Grenningloh G, Rehm EJ, Goodman CS (1991) Genetic analysis of growth cone guidance in Drosophila: fasciclin II functions as a neuronal recognition molecule. Cell 67:45-57.

Grotewiel MS, Beck CDO, Wu KH, Zhu XR, Davis RL (1998) Integrin-mediated short-term memory in Drosophila. Nature 391:455-460.

Hynes RO (1996) Targeted mutations in cell adhesion genes: what have we learned from them? Dev Biol 180:402-412.

Jay D (1996) Molecular mechanisms of directed growth cone motility. Perspect Dev Neurobiol 4:137-145.

Jones LS (1996) Integrins: possible functions in the adult CNS. Trends Neurosci 19:68-72.

Kuhn TB, Schmidt MF, Kater SB (1995) Laminin and fibronectin guideposts signal sustained but opposite effects to passing growth cones. Neuron 14:275-285.

Kuhn TB, Williams CV, Dou P, Kater SB (1998) Laminin directs growth cone navigation via two temporally and functionally distinct calcium signals. J Neurosci 18:184-194.

Lallier TE, Whittaker CA, DeSimone DW (1996) Integrin $\alpha 6$ expression is required for early nervous system development in Xenopus laevis. Development 122:2539-2554.

Leptin M, Bogaert T, Lehmann R, Wilcox M (1989) The function of PS integrins during Drosophila embryogenesis. Cell 56:401-408.

Li X, Graner MW, Williams EL, Roote CE, Bunch TA, Zusman S (1998) Requirements for the cytoplasmic domain of the $\alpha \mathrm{PS} 1, \alpha \mathrm{PS} 2, \beta \mathrm{PS}$ integrin subunits during Drosophila development. Development 125:701-711.

Lin C-H, Forscher P (1995) Growth cone advance is inversely proportional to retrograde F-actin flow. Neuron 14:763-771.

Lin CH, Thompson CA, Forscher P (1994) Cytoskeletal reorganization underlying growth cone motility. Curr Opin Neurobiol 4:640-647.

Lin DM, Fetter RD, Kopczynski C, Grenningloh G, Goodman CS (1994) Genetic analysis of fasciclin II in Drosophila: defasciculation, refasciculation, and altered fasciculation. Neuron 13:1055-1069.

MacKrell AJ, Blumberg B, Hynes SR, Fessler JH (1988) The lethal myospheroid gene of Drosophila encodes a membrane protein homologous to vertebrate integrin beta subunits. Proc Natl Acad Sci USA 85:2633-2637.

Martin PT, Kaufman SJ, Kramer RH, Sanes JR (1996) Synaptic integrins in developing, adult, and mutant muscle: selective association of $\alpha 1, \alpha 7$, and $\alpha 7 \beta$ integrins in the neuromuscular junction. Dev Biol 174:125-139.

Martin-Bermudo MD, Dunin-Borkowski OM, Brown NH (1997) Specificity of PS integrin function during embryogenesis resides in the $\alpha$ subunit extracellular domain. EMBO J 16:4184-4193.

Montell DJ, Goodman CS (1989) Drosophila laminin: sequence of $\beta 2$ subunit and expression of all three subunits during embryogenesis. J Cell Biol 109:2441-2453.

Parsons JT (1996) Integrin-mediated signaling: regulation by protein tyrosine kinases and small GTP-binding proteins. Curr Opin Cell Biol 8:146-152.

Roote CE, Zusman S (1996) Alternatively spliced forms of the Drosophila $\alpha \mathrm{PS} 2$ subunit of integrin are sufficient for viability and can replace the function of the $\alpha \mathrm{PS} 1$ subunit of integrin in the retina. Development 122:1985-1994.

Schlaepfer DD, Hunter T (1998) Integrin signalling and tyrosine phosphorylation: just the FAKs? Trends Cell Biol 8:151-157.

Schmidt CE, Dai J, Lauffenburger DA, Sheetz MP, Horwitz AF (1995) Integrin-cytoskeletal interactions in the neuronal growth cones. J Neurosci 15:3400-3407.

Shaw CE, Milner R, Compston AS, French-Constant C (1996) Analysis of integrin expression on oligodendrocytes during axo-glial interaction by using rat-mouse xenoculture. J Neurosci 16:1163-1172.

Sone M, Hoshino M, Suzuki E, Kuroda S, Kaibuchi K, Nakagoshi H, Saigo K, Nabeshima Y, Hama C (1997) Still life, a protein in synaptic terminals of Drosophila homologous to GDP-GTP exchangers. Science 275:543-547.

Speicher S, Garcia-Alonso L, Carmena A, Martin-Bermudo M, de la Escalera S, Jimenez F (1998) Neurotactin functions in concert with other identified CAMs in growth cone guidance in Drosophila. Neuron 20:221-233.

Stark KA, Yee GH, Roote CE, Williams EL, Zusman S, Hynes RO (1997) A novel $\alpha$ integrin subunit associates with $\beta$ PS and functions in tissue morphogenesis and movement during Drosophila development. Development 124:4583-4594.

Takagi Y, Ui-Tei K, Miyake T, Hirohashi S (1998) Laminin-dependent integrin clustering with tyrosine-phosphorylated molecules in a Drosophila neuronal cell line. Neurosci Lett 244:149-152.

Treubert U, Brummendorf $\mathrm{T}$ (1998) Functional cooperation of $\beta 1$ integrins and members of the Ig superfamily in neurite outgrowth induction. J Neurosci 18:1795-1805.

Varnum-Finney B, Venstrom K, Muller U, Kypta R, Backus C, Chiquet M, Reicharrdt LF (1995) The integrin receptor $\alpha 8 \beta 1$ mediates interactions of embryonic chick motor and sensory neurons with Tenascin-C. Neuron 14:1213-1222.

Wehrli M, DiAntonio A, Fearnley I, Smith R, Wilcox M (1993) Cloning and characterization of $\alpha \mathrm{PS} 1$, a novel Drosophila melanogaster integrin. Mech Dev 43:21-36.

Wilcox M (1990) Genetic analysis of the Drosophila PS integrins. Cell Differ Dev 32:391-400.

Wilcox M, Brower DL, Smith RJ (1981) A position-specific cell surface antigen in the Drosophila wing imaginal disc. Cell 25:159-164.

Wilcox M, DiAntonio A, Leptin M (1989) The function of PS integrins in Drosophila wing morphogenesis. Development 107:891-897.

Wu DY, Wang LC, Mason CA, Goldberg DJ (1996) Association of $\beta 1$ integrin with phosphotyrosine in growth cone filopodia. J Neurosci 16:1470-1478.

Yee GH, Hynes RO (1993) A novel, tissue-specific integrin subunit, $\beta \mathrm{v}$, expressed in the midgut of Drosophila melanogaster. Development 118:845-858.

Zusman S, Patel-King RS, French-Constant C, Hynes RO (1990) Requirements for integrins during Drosophila development. Development 108:391-402. 